\title{
Detection System Design of Subsea Tree CONTROLLER
}

\author{
Xie Yang and Cheng Wushan \\ College of Mechanical Engineering, Shanghai University of Engineering Science, \\ Shanghai 201620, China
}

\begin{abstract}
To meet the requirements of the detection system of underwater controller of subsea tree, this paper adopts the data acquisition and control mode of "HMI+ SIEMENS PLC+SQL ". Using the configuration software, completed the development and design of production tree detection system to monitor, control and data communication. The monitoring function has realized the process simulation of oil tree, the control function has realized the remote control of oil tree, and database SQL has realized the management and analysis of data in oil well, achieving real-time tracking, rapid response, improve speed, quality and reporting level of oil production engineering design. At the same time the design center can make full use of the database to complete the design of required query, statistical analysis and the output function of related form.
\end{abstract}

\section{KEYWORDS}

Subsea Tree, Underwater Controller, Detection System, HMI, SQL.

\section{INTRODUCTION}

Subsea production systems as the most central part of deep water oilfield, how to develop a reasonable test requirements and test methods to ensure their effectiveness, safety and reliability features in the process of work, is one of the key technologies of deep-sea oil and gas field development. Subsea production system consists of a master station, hydraulic power station, umbilical, umbilical distribution unit, subsea trees, manifolds, underwater jumper, subsea control systems and other components, and each subsystem contains a variety of cell components. Therefore, the test needs subsea production systems, including basic unit testing, subsystem factory acceptance testing, system integration testing on-site acceptance testing and commissioning etc. ${ }^{[1]}$.

\section{System COMPONENTS AND PROCESSES}

Subsea tree is mainly used for the control of wellhead pressure and flow during the production of oil wells, while taking into account a variety of test and implement of oil production measures, therefore, its safety must be fully guaranteed. Because of subsea tree placed in the deep for long, the important and effective means of plant safety evaluation for subsea tree is on the testing of underwater controller of subsea tree, among them, the communication between the underwater controller and subsea tree is shown in Figure 1. In order to ensure that the entire detection system is safe and reliable operation, the system will employ configuration design combining monitoring and control functions ${ }^{[2]}$. 


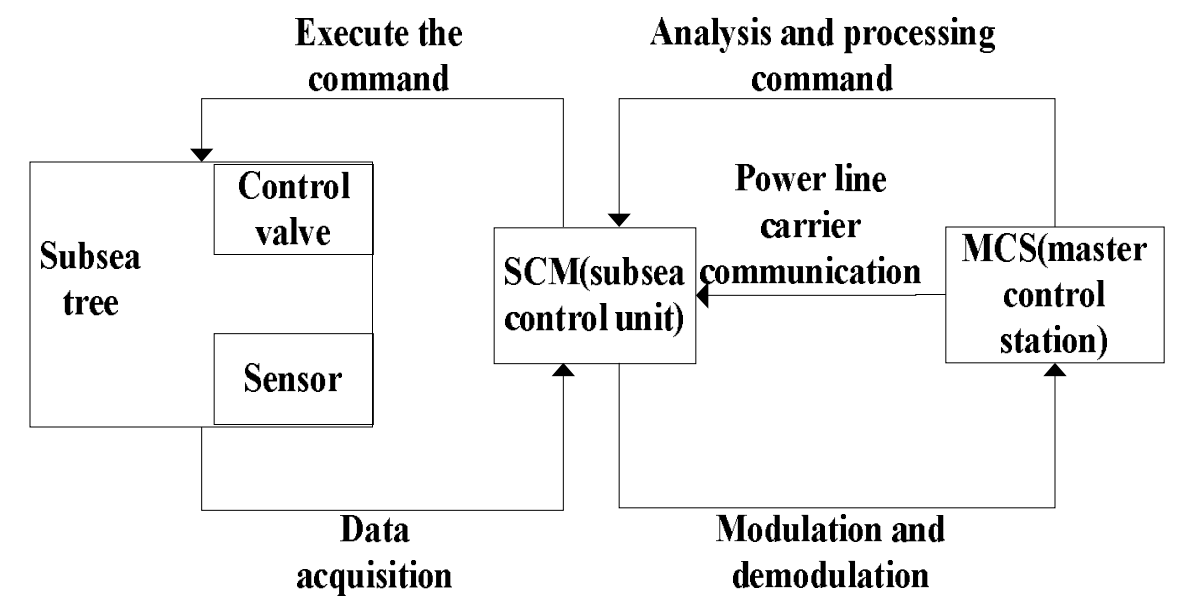

Figure 1. Schematic of underwater communication controller

Subsea tree is responsible for the main circuit work throughout the oil and gas exploration, production flow can be adjusted to control the total production. Annulus circuit is mainly used for the discharge of down hole leaked oil and gas of subsea tree, under normal circumstances, this circuit is in a standby state. When the subsea tree work, annulus loop pipeline valve is normally closed, it is controlled by underwater electro-hydraulic valve of SCM to drive the valve open. When the casing and tubing leaks, down hole pressure sensor will transmit the measured data back to the SCM, SCM then transmits the signal to the master station MCS, after analyze and treatment of MCS, if found pressure exceeds a certain value, MCS will issue control instructions to the SCM, SCM opens the annulus main valve.

Chemical injection circuit is divided into three parts: the scale inhibitor, ethylene glycol and methanol injection circuit. Chemicals is from the water platform, ground electro-hydraulic distributor TUTA will transfer chemicals to the underwater electro-hydraulic distributor SUTU through the umbilical, underwater electro-hydraulic distributor then injects different chemicals into the wellbore submarine pipeline or pipeline of subsea tree, different chemicals play a role in cleaning, freezing and wax.

SCM will upload the injection metering valve data to MCS, after the processing and analysis of the data, less than the set value, MCS will increase in traffic of platform chemicals; greater than the set value, MCS will reduce in flow of platform chemicals. Inhibitor is injected to the bottom of the subsea tree through an underwater electro-hydraulic distributor, SCM acquires the data of inhibitor injection metering valve to control the chemical injection valves open and close, playing a role in cleaning. Ethylene glycol is injected to the main loop of subsea tree through an underwater electro-hydraulic distributor, SCM collects the data of glycol injection metering valve to control the chemical injection valves open and close, to play the role of antifreeze. Methanol is injected directly into the main circuit by underwater electro-hydraulic distributor, in the absence of a metering valve, methanol loop has been in a normally open state, playing the role of wax. Schematic in Figure 2. 
International Journal of Computer Science \& Engineering Survey (IJCSES) Vol.5, No.5/6, December 2014

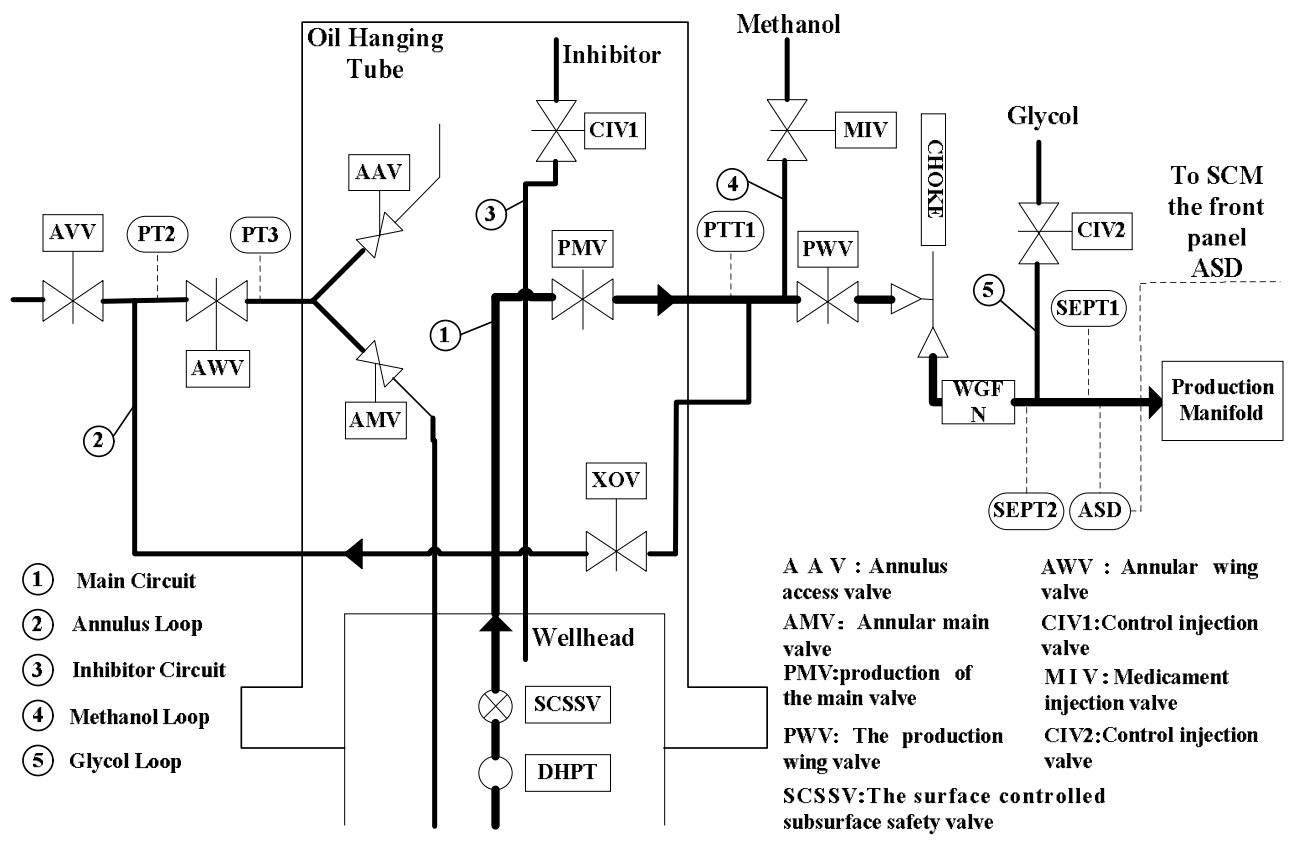

Figure 2. Map production principle of subsea tree

\section{Monitoring System Design}

\subsection{Monitoring System}

The design of monitoring system of underwater controller of subsea tree contains determining engineering framework, graphics production interface, process control, storage capabilities and security mechanisms. The structure of monitoring system is shown in Figure 3.

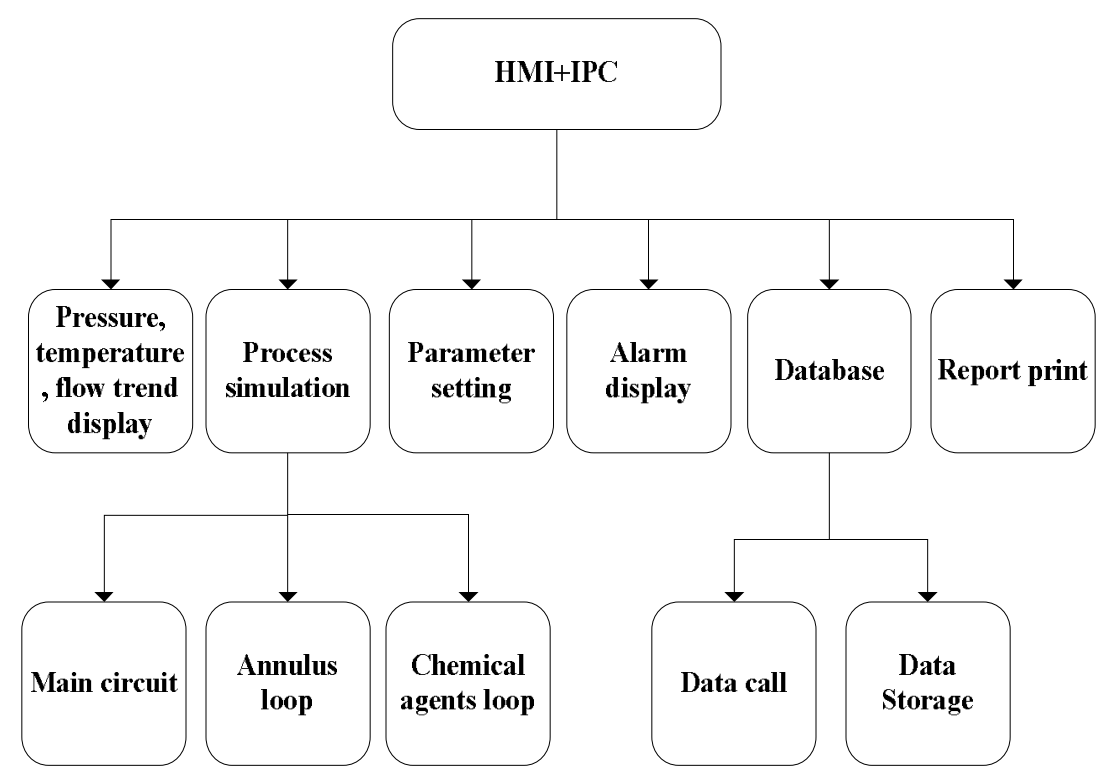

Figure 3. The structure of monitoring system 


\subsection{Monitoring Software Design}

The detection system of underwater controller includes control panel, underwater controller, the main loop, the annulus loop, pharmacy loop, alarm unit and report printing. This test system has the following features:

(1)Achieving the simulation of production processes: the interface design of the controller under water makes the working flow of the subsea tree can be seen intuitively, which includes main loop, annular loop, glycol circuit, scale inhibitor and methanol loop circuit. Using the configuration system to develop a dynamic extraction process of display interface, which is capable of real-time simulation of a whole process flow, simultaneously, convenient for field personnel to operate;

(2)The standardization of screen design, the modular of functional planning: pictures are based on ergonomic principles and working long hours to minimize fatigue. Function module designs logically, to minimize duplication operation, misuse and other invalid operation. To monitor whether the excessive amount of critical, real-time alarm or reminder in this design by the alarm unit of configuration software, the valve work range of 5\% 95\%, less than 5\% for the lower limit alarm, higher than $95 \%$ for the upper limit alarm, the alarm limit data for $80 \%$ of range.

(3)SQL database query: through the connection of configuration software and SQL database, the interface can display information of database, different time, date and the amount of collected information corresponding to different interface. The definition of dynamic data link in the development of configuration software system makes the picture and display the data in the operating environment can be updated in real time with the change of the data.

(4)Monitoring interface is shown in Figure 4.

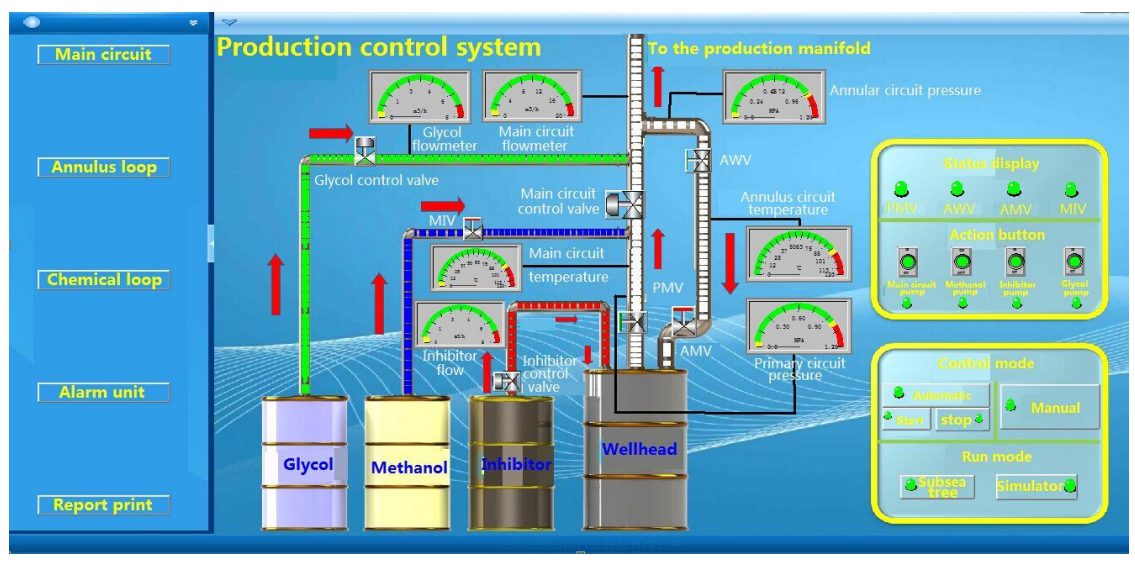

Figure 4. Monitoring interface

\subsection{Control Software Design}

Using computer monitoring software combined with PLC by connecting the control buttons and the variables of PLC to achieve the control of the system:

(1)In the configuration software design of the control panel, different colors to distinguish the different control states;

(2)Programming for the designed control button achieves the aim of controlling; 
(3)Display box shows the variable amount which is connected to the amount defined in configuration software, trend display controls added configuration variables;

(4)PLC has two kinds of programming model: automatic and manual control. During automatic operation, the main circuit of the regulating valve is opened slowly. Interface appears water flow when opening $>13 \%$, the opening value greater the flow more quickly and more broadly. When opening value reach 95\%, ethylene glycol regulating valve, scale inhibitor regulating valve and the on-off valve open at the same time, also, the opening degree of the regulating valve $>13 \%$ interface appears water flow, and the opening value greater the flow more quickly and more broadly. When ethylene glycol regulating valve and the scale inhibitor regulating valve is opened and the value reach to $95 \%$, the main loop water pump, methanol pump, ethylene glycol pump , inhibitor pump open, and system is in normal operation conditions. If you want to switch to manual mode, first click the stop automatic mode, and then click manual control, specific control process in Figure 5.

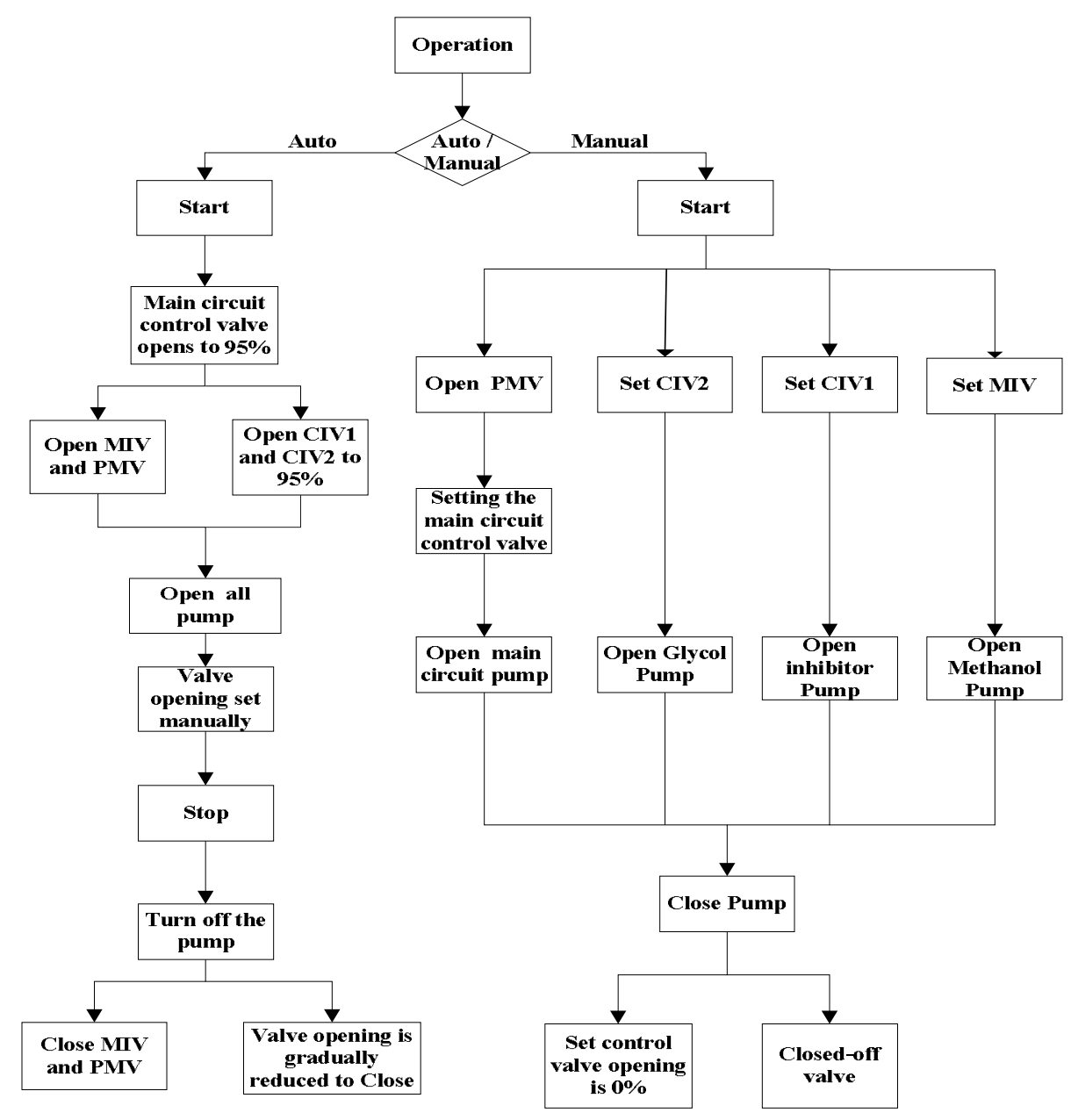

Figure 5. The flow chart of control mode

\section{COMmunication Design}

There are two kinds of communication mode in this design: communication between configuration software and database, configuration software and PLC. Through the connection 
configuration software and database of SQL, configuration software will read directly data gathered by the sensor to the database.

\subsection{Communication between software and database configuration}

(1) The definition of variables

To achieve the connections between configuration software and database, connections between the variables in the data dictionary of configuration software have been already established, such as, the establishment of Device ID, the main circuit of the variable temperature, the main circuit pressure, the flow of main loop, the temperature of annulus loop, pressure, flow, scale inhibitor for ethylene glycol flow of these eight variables. Where Device ID is the memory integer, the rest is $\mathrm{I} / \mathrm{O}$ real.

(2) Create a form template E \# table, as shown in Table 1.

Table 1. Template form

\begin{tabular}{|l|l|l|}
\hline Variable name & Variable types & Variable length \\
\hline Date & Fixed-length string & 50 \\
\hline Time & Fixed-length string & 50 \\
\hline Main circuit temperature & Float & 1 \\
\hline Primary circuit pressure & Float & 1 \\
\hline Main loop flow & Float & 1 \\
\hline Annulus circuit temperature & Float & 1 \\
\hline Annulus circuit pressure & Float & 1 \\
\hline Glycol flow & Float & 1 \\
\hline Inhibitor flow & Float & 1 \\
\hline
\end{tabular}

(3) Create a record body bind5, as shown in Table 2.

Table 2. Records body form

\begin{tabular}{|c|c|}
\hline Field Name & Variable name \\
\hline Date & \ISite $\backslash \$$ Date \\
\hline Time & $\backslash \backslash$ Site $\backslash \$$ Time \\
\hline Main circuit temperature & $\backslash \backslash$ Site $\backslash$ main circuit temperature \\
\hline Primary circuit pressure & $\backslash \backslash$ Site $\backslash$ primary circuit pressure \\
\hline Main loop flow & \I Site $\backslash$ main loop flow \\
\hline Annulus circuit temperature & \ISite $\backslash$ annulus circuit temperature \\
\hline Annulus circuit pressure & \\
Site $\backslash$ annulus circuit pressure \\
\hline Glycol flow & $\backslash \backslash$ Site $\backslash$ glycol flow \\
\hline Inhibitor flow & \\
Site \inhibitor traffic \\
\hline
\end{tabular}

(4) Establishment of a database and set up an ODBC data source.

Select the ODBC data source management tool in the control panel, on the users tab, click the Add button, select SQL database, after the completion of filling in the mine data source name, press the select button to select the created database SQL.

(5)Data Command Language Programming

Database connection: SQL Create Table (Device ID, "E\# table", "E\# table"); 
Create a database table: SQL Insert (Device ID, "E\# table", "bind5");

Disconnect the database: SQL Disconnect (Device ID);

\subsection{Communications software and PLC configuration}

Communication of IPC and PLC: using PPI communication of SIEMENS PLC series S7200 configuration software. 9600 baud rate, 1 check bit, data bit 8, stop bit 1, RS232, COM1 serial communication mode, the device address 2 , the rest is set to the default parameter.

\section{TEST RESULTS}

Underwater production tree controller detection after the preparations, restart your computer, double-click the desktop icon into the monitoring software of monitoring software main interface, can process according to click on the corresponding button on the control of each device detecting and controlling water under manual control at any time can be observed on the equipment operation; operation and test data in the monitoring interface, if the manual control state switches to automatic operation state, the system will enter the PLC programmed automatic process running ${ }^{[7]}$, reading from the database data. As shown in Table 3, data from the test verifies the design reliability and stability.

Table 3 Test results

\begin{tabular}{|l|l|l|l|l|l|l|l|l|}
\hline & & $\begin{array}{l}\text { Main } \\
\text { circuit } \\
\text { temper } \\
\text { ature } \\
I^{\circ} \mathrm{C}\end{array}$ & $\begin{array}{l}\text { Primary } \\
\text { circuit } \\
\text { pressur } \\
\text { e /MPA }\end{array}$ & $\begin{array}{l}\text { Annulu } \\
\text { s circuit } \\
\text { tempera } \\
\text { ture } /{ }^{\circ} \mathrm{C}\end{array}$ & $\begin{array}{l}\text { Annulus } \\
\text { circuit } \\
\text { pressure } \\
\text { /MPA }\end{array}$ & $\begin{array}{l}\text { Main } \\
\text { loop } \\
\text { flow } /(\mathrm{m} / \mathrm{h})\end{array}$ & $\begin{array}{l}\text { Inhibitor } \\
\text { flow }(\mathrm{m} \\
3 / \mathrm{h})\end{array}$ & $\begin{array}{l}\text { Glycol } \\
\text { flow } \\
\left(\mathrm{m}^{3} / \mathrm{h}\right)\end{array}$ \\
\hline $\begin{array}{l}2014-5- \\
30\end{array}$ & $\begin{array}{l}04: 49: \\
04\end{array}$ & $\begin{array}{l}32.492 \\
187\end{array}$ & $\begin{array}{l}\text { Time } \\
8\end{array}$ & $\begin{array}{l}32.8828 \\
12\end{array}$ & 0.001992 & 3.40781 & 0.77937 & 0.8243 \\
5 & 75 \\
\hline $2014-5-$ & $04: 49:$ & 32.496 & 0.02011 & 32.8828 & & 5.41015 & 0.77937 & 0.8246 \\
30 & 05 & 093 & 7 & 12 & 0.001992 & 6 & 5 & 87 \\
\hline $2014-5-$ & $04: 49:$ & 32.496 & 0.02097 & 32.8867 & & 5.39765 & 0.77906 & 0.8243 \\
30 & 06 & 093 & 7 & 2 & 0.001992 & 6 & 3 & 75 \\
\hline $2014-5-$ & $04: 49:$ & & 0.02136 & 32.8867 & & 5.40859 & 0.77781 & 0.8231 \\
30 & 07 & 32.5 & 7 & 2 & 0.001953 & 4 & 2 & 25 \\
\hline $2014-5-$ & $04: 49:$ & & 0.02121 & 32.8906 & & 5.40312 & 0.77937 & 0.8243 \\
30 & 08 & 32.5 & 1 & 25 & 0.001992 & 5 & 5 & 75 \\
\hline $2014-5-$ & $04: 49:$ & & 0.02105 & 32.8906 & & 5.40781 & 0.77843 & \\
30 & 09 & 32.5 & 5 & 25 & 0.001992 & 3 & 7 & 0.825 \\
\hline $2014-5-$ & $04: 49:$ & 32.503 & 0.02121 & 32.8945 & & 5.40468 & 0.78093 & 0.8240 \\
30 & 10 & 906 & 1 & 3 & 0.001953 & 7 & 7 & 63 \\
\hline $2014-5-$ & $04: 49:$ & 32.503 & 0.02109 & 32.8945 & & 5.39687 & 0.78187 & 0.8253 \\
30 & 11 & 906 & 4 & 3 & 0.001992 & 5 & 5 & 12 \\
\hline $2014-5-$ & $04: 49:$ & 32.507 & 0.02121 & 32.9023 & & 5.40859 & 0.77937 & 0.8256 \\
30 & 12 & 812 & 1 & 43 & 0.002031 & 4 & 5 & 25 \\
\hline
\end{tabular}

\section{Conclusions}

The development of oil resources of marine is a research and development strategic plan in the current stage, in order to ensure the safe operation of the equipment of oil and gas resources 
development in deep waters, the concrete research about detection system for underwater controller in this paper obtained the following conclusions ${ }^{[8-10]}$ :

(1)According to the production facilities of monitoring system of water under the functional requirements, the interface of monitoring system based on configuration software is designed, users can more intuitively and accurately operated underwater production facilities.

(2)Underwater production tree controller detection system experiments proved that the stability, accuracy and safety of the monitoring system in the data acquisition, process control and other aspects. Development and application of the controller detection and monitoring system of subsea tree provide an effective method for automatic control of various mechanical equipment, test equipment and process flow. This data acquisition and control method mainly includes the following technical features: configuration software programming is flexible, convenient, and the configuration interface design provides a vivid image, the same time, with fast computer data storage and processing, and growing large capacity function; PLC data acquisition and control have favour performance in reliability, and the compatibility of communication with computer. Combining effectively these advantages of technology together to develop a variety of reliable data acquisition and control systems.

\section{REFERENCES}

[1] Su Feng, Liu Hongyan, Wang Qiang,(2008) Application on Transportation of Electrical Power/Signal in the Underwater Production System[J], Automation in Petro-Chemical Industry, No.5, pp29-31.

[2] Jia Guangzheng,Li Mangtian, Wang Jinyou, Zhang Shujin,(2009) Monitor and Control System of Hydrostatic Testing for Christmas Tree Equipment[J], Machinery \& Electronics, No.4, pp40-42.

[3] Tang Yan, Lin Jingdong, Qu Yingying,(2010)Statistical Data Report Based on SQL Access Functions of Kingview[J], Journal of Jiamusi University (Natural Science Edition), No.3, pp346-348.

[4] Tang Mingmei, Tang Xiaorong,(2014) Design of Production Process Database System Based on PLC and KingView[J],Machine Tool \& Hydraulics, No.2, pp115-116.

[5] Sun Mingge, Zhu Xilin,(2006) SQL Database Technology based on Configuration King Software[J], Control \& Automation, No.7, pp109-111.

[6] Yin Minghong, Zhu Jianyong,(2008) Transmission through KINGVIEW Software and SQL Database[J], Nonferrous Metals Engineering\& Research, No.5, pp40-41.

[7] Cao Zheguang,(2013) Research on Subsea Production Facilities Monitoring System Based on WinCC[D], Harbin Engineering University.

[8] Yu Junjie, Zhang Wei, Xia Ling, Sun Yun, Yang Houtai, Qian Xuefeng,(2014)PLC and HMI Applications in the Network Control[J],Control and Instruments in Chemical Industry, No.3, pp344346.

[9] Song Yanghui,(2013) Design \& Implementation of Monitoring System of Oil-Water Wells in NO.7 Oil Production Plant of Plant of DaQing Oil Field[D] School of Information and Software Engineering.

[10] Liu Kai,(2012)Research and Implementation of Human-machine Interface based on Data-driven and Business Rule XIDIAN University.

\section{Author}

Corresponding author: Xie Yang (1990-), male, master of engineering, research direction for robotics and intelligent control.

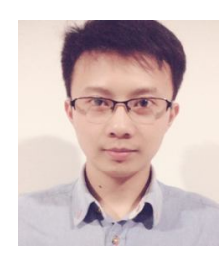

